\title{
IMUNIZAÇÃO DE CAMUNDONGOS COM «VACINA» VIVA AVIRULENTA DE TRYPANOSOMA CRUZI
}

\author{
I - Ensaio da avaliação do menor inoculo eficiente.
}

\author{
Hunherto Menezes *
}

o Autor procura verificar qual o menor número de Trypanosoma cruzi, da cepa $Y$ avirulenta, capaz de conferir a camundongos imunidade eficiente contra uma ulterior infecção com a cepa $Y$ virulenta do mesmo parasita. boçadas.

Em trabalhos anteriores procuramos demonstrar o efeito protetor de uma cepa avirulenta do Trypanosoma cruzi contra infecção experimental com cepa altamente virulenta do mesmo flagelado $(7,11,13)$

Naqueles trabalhos foi utilizado, deliberadamente, um inóculo muito grande, pois o objetivo era duplo: mostrar o papel imunizante da vacina usada e ao mesmo tempo a sua avirulência.

Visando uma possível aplicação prática posterior procuramos avaliar a quantidade mínima de tripanosomas avirulentos capaz de proteger eficientemente camundongos contra uma infecção virulenta.

\section{MATERIAL E MÉTODOS}

Utilizamos como "vacina" uma cultura de Trypanosoma cruzi, cepa $\mathrm{Y}$, mantida em meio de cultura də Packchanian( subinoculação n. ${ }^{\circ} 306$ do Departamento de Parasitologia da F.M.R.P.), com 28 dias de idade.

O líquido de condensação do meio foi centrifugado e o sedimento suspenso em solução salina, centrifugado várias vêzes, à baixa roteção, até se obter um sobrenadante límpido.

O sedimento foi mais uma vez suspenso em solução salina, tendo sido feita imediatamente uma avaliação do número de formas vivas presentes, calculando-se estas em cêrca de $60 \%$ de todos os parasitas.

Deixou-se secar uma gôta de "vacina" sôbre uma lâmina e posteriormente procedeu-se a uma coloração pelo Giemsa.

Com o auxílio de uma ocular integradora Zeiss e tendo como padrão um esfregaço de sangue cujo número de hemácias por $\mathrm{mm}$ " era conhecido, procedeu-se à estimativa do número de parasitas por $\mathrm{ml}$.

A mesma lâmina examinada com imersão permitiu avaliar o percentual de formas metacíclicas.

Dêsse modo calculou-se que $1 \mathrm{ml}$ da vacina possuia: $2,4 \times 10^{\text {si }}$ parasitas dos quais $60 \%$ estavam vivos. As formas metacíclicas correspondiam mais ou menos a $10 \%$ dos tripanosomas presentes na preparação.

A "vacina" foi então dividida em quatro frações sendo não diluida a primeira $\mathrm{e}$ as demais diluidas a 1/10,1/100 e 1/1000, sucessivamente. sil. 


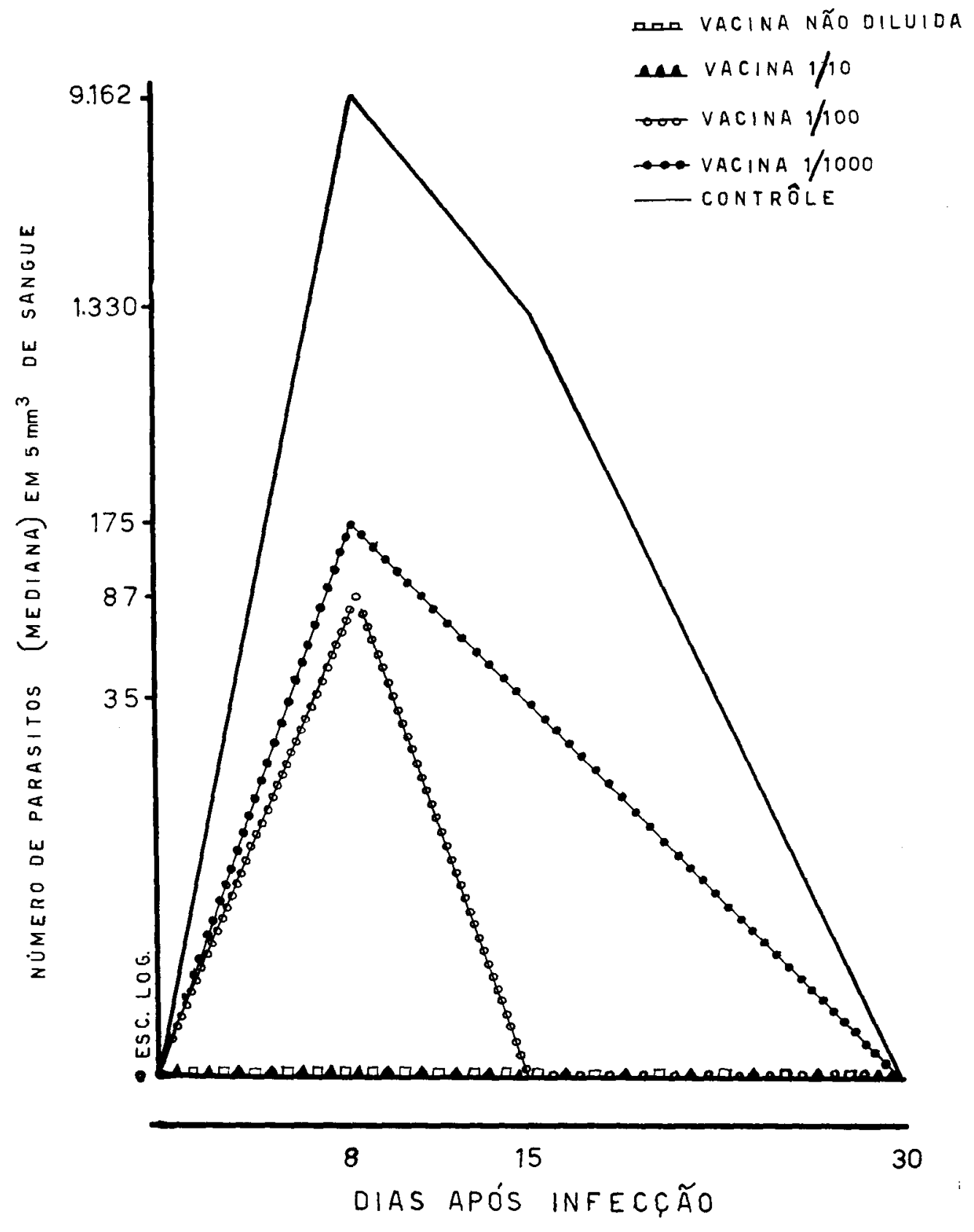




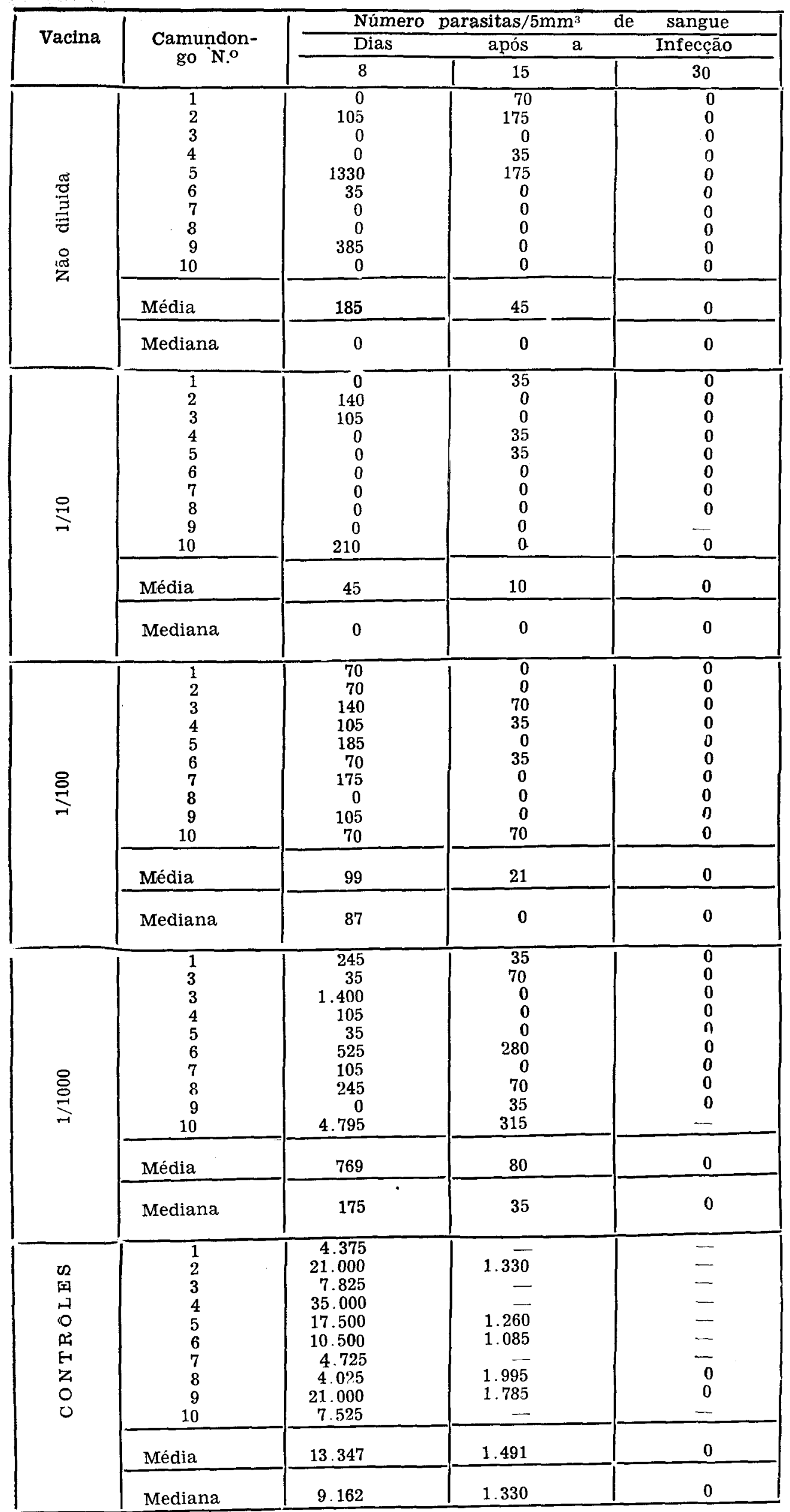


Quarenta camundongos albinos, machos, com $10 \mathrm{~g}$ de pêso foram divididos em grupos de 10 e a cada grupo se injetou, por via subcutânea, $0,2 \mathrm{ml}$ de uma das fraçōes da "vacina".

Dez animais da mesma procedência, pêso e sexo, mantidos nas mesmas condições, foram tomados como contrôles.

Pela técnica da gôta espêssa fizemos uma pesquisa de tripanosomas no sangue periférìco de todos os animais "vacinados", 8 e 15 dias após a "Vacinação".

Quatro semanas após a imunização todos os animais, inclusive os contrôles, foram infectados, por via peritoneal, com 5.000 tripanosomas/g de pêso.

Os flagelados infectantes provinham de sangue heparinizado de camundongos no 8. dia da infecção com a cepa virulenta $Y$ do Trypanosoma cruzi.

A parasitemia de todos os animais foi feita no $8 .^{\circ}, 15 .^{\circ}$ e $30 .^{\circ}$ dias após a infecção, usando-se a técnica da contagem preconizada por Pizzi e modificada por Brener (1).

O percentual de sobrevida dos animais foi tomado também em relação com aquelas datas.

\section{RESULTADOS}

Os resultados obtidos se acham resumidos na Tabela 1 e nos Gráficos I e III.

Por êles se verifica que tôdas as fraçōes da "vacina" protegeram os animais, contudo as que conferiram melhor proteção foram as possuídoras de maior número de parasitas. Os animais imunizados com "vacina" não diluida e diluida a 1/10 não chegaram sequer a apresentar, na sua maioria, parasitemia após a infecção.

Um dos animais protegidos com a "vacina" a 1/10 morreu no $17 .^{\circ}$ dia pós infecção e embora não tenhamos feito estudo histopatológico, dado o estado de putrefação em que foi encontrado, é quase certo não ter morrido da parasitemia, pois tivera duas parasitemias negativas nos dias 8 e 15 após a infecção.

Os animais protegidos com a "vacina" a $1 / 1000$ que teòricamente receberam 288 tripanosomas vivos, sendo 29 formas metacíclicas, tiveram uma parasitemia discreta (exceção de dois animais) no $8^{\circ}$ e $15 .^{\circ}$ dia e negativa no $30^{\circ}$.
A única morte dêsse grupo se deveu, de fato, à infecção tripanosomótica e ocorreu no $16 .^{\circ}$ dia pós infecção.

Quanto aos contrôles comportaram-se como todos os outros das demais experiências nossas em que utilizamos a mesma cepa e a mesma dose infectante $(6,7,11$, $13)$; i.é., apresentaram uma alta parasitemia no 8. dia que foi declinando até se tornar negativa no $300^{\circ}$ dia.

A mortalidade se iniciou no $15 .^{\circ}$ dia pós infecção e se tornou máxima no $21 .^{\circ}$ dia, conservando o mesmo percentual até o $300^{\circ}$ dia quando a experiência foi considerada encerrada.

As pesquisas parasitárias pós vacinação e pré-infecção foram tôdas negativas.

\section{COMENTÁRIOS E CONCLUSÓES}

Embora seja possivel que venhamos a ter dentro em breve vacinas mortas eficientes contra a tripanosomose sul-americana $(2,4$ e 14), os melhores resultados verificados até agora têm sido com as "vacinas" vivas.

Ainda se encontra arraigado no espirito da maioria dos parasitologistas que se dedicam ao estudo da imunidade dessa parasitose, o princípio elaborado em 1931 por Collier (3) de que a imunidade dos animais de laboratório, infectados, está na dependência da presença permanente do parasita no tecido somático.

A "premunição" que é o têrmo dado a êsse tipo de imunidade é, na opinião de Lumsden (5) um têrmo meramente descritivo, nada significando quanto ao mecanismo imunitário.

Êste, segundo o mesmo Autor, deve ser semelhante tanto nas infecçōes parasitárias como nas viróticas e bacterianas.

No nosso caso estamos convictos de que os parasitas vivos avirulentos usados para imunizar os animais, produzem uma infecção transitória nos mesmos, mas não uma infecção-doença.

Em nenhuma oportunidade conseguimos evidenciar, pelas técnicas usuais de parasitologia e de histologia, parasitas nos animais, quatro semanas após a "vacinação" $(6,7,8,9,10,11,12$ e 13), embora os mesmos estivessem capacitados a resistir a uma infecção com cepa virulenta. Tudo nos leva a crer que a estrutura antigênica do $T$. cruzi é extremamente lábil e que 


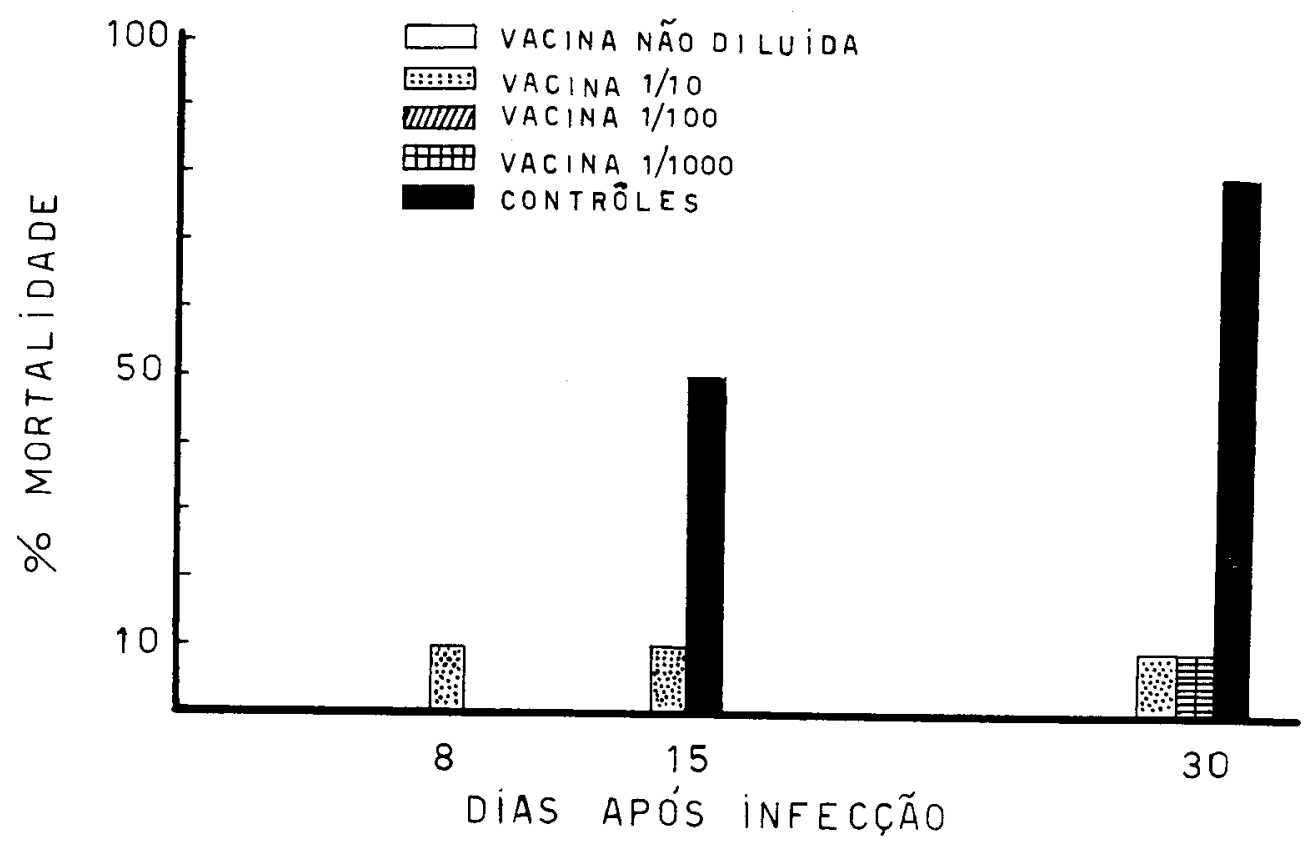

qualquer tratamento seja por processos químicos ou físicos induz alteraçōes com perda ou diminuição acentuada do seu podèr înürnogêtrico.

Com os tripanosomas vivos da cepa avirulenta os antígenos seriam levados, inalterados, ao interior das células, sem contudo se multiplicarem nas mesmas.

Dêsse modo se desenvolveriam os fenômenos imunitários sem que houvesse doença.

Segundo esta linha de pensamento, admitimos que seja possivel, com técnicas refinadas, a obtenção de antígenos com um mínimo de alterações estruturais, capazes de induzir eficiente resposta imunológica.

Até que tal objetivo seja atingido de modo prático, a existência de uma cepa avirulenta, com elevada capacidade imunizante, se nos afigura como a maneira mais segura de se obter uma adequada proteção dos mamíferos contra infecção pelo Trypanosoma cruzi.

Tôdas as provas laboratoriais realizadas agora ( 9 e 10) mostram que a cepa $Y$ cultivada perdeu realmente a capacidade de infectar animais de laboratório, seja qual for a dose e a via empregada.

Como conclusão do presente trabalho verificou-se que aparentemente o grau de proteção (medido sobretudo pelo grau de parasitemia) parece relacionado com um maior número de parasitas vivos inoculados. Essa relação não teria um caráter exponencial pois pequenas quantidades de tripanosomas são capazes de conferir bom estado de proteção (especialmente se se toma como padrão o percentual de sobrevida), muito próximo daquele conseguido com altíssimas doses de parasitas. 


\section{$S U M M A R Y$}

After having demonstrated that the cultivated $Y$ strain of Trypanosoma cruzi became avirulent to laboratory animals without losing its protective activity against a further virulent infection, the Author concludes that a very small dose of live trypanosomes (about 3 metaciclic forms per gram of body weight) is able to afford good immunity to mice. General considerations about the probable mechanism of the immunity are made.

\section{BIBLIOGRAFIA}

1. BRENER, Z. - Contribuição ao estudo da terapêutica experimental da Doenca de Chagas. Tese. Fac. Farm. Odont. Univ. Minas Gerais, Belo Horizonte, 1961 .

2. CAPPA, S.M.G.; SCHMUNIS, G.A.; TRAVERSA, O.C.; YAVANOVSKY, J.F. \& PARODI, A.S. - Complement fixation tests skin test and experimental immunization with antigens of $T$. cruzi prepared under pressure. Am. J. Trop. Med. \& Hyg. 17: .... $709-715,1968$.

3. COLLIER, W. - Über Immunität bei du Chagas Krankheit du Weissen mans. Z. Hyg. Infektionskr. 112: .. 88-92, 1931.

4. GOBLE, F.C. - Experimental immunology 8th $^{\text {th }}$ Int Cong. Trop. Med. \& Malaria. Teheran. 1968. Abstracts \& Reviews. Pág. 366.

5. LUMSDEN, W.H.R. - Trends in Research on the Immunology of Trypanosomias. Bull. Wld. Hlth. Org. 37: $167-175,1967$.

6. MENEZES, $H$. - The effect of phenolated "vaccines" against experimental infection in mice. Rev. Inst. Med. Trop. São Paulo, 2:59-66 1968.

7. MENEZES, H. - Protective effect of on avirulent (Cultivated) strain of Trypanosoma cruzi against experim- ental infection in mice. Rev. Inst. Med. Trop. São Paulo, 10: 1-4, 1968.

8. MENEZES, H. - Lesões histológicas em camundongos "vacinados" com uma cepa avirulenta do Trypanosoma cruzi. Rev. Brasil. Med. 25: 160-165, 1968.

9. MENEZES, H. - I - The avirulence of the cultivated $\mathbf{Y}$ strain of Trypanosoma cruzi. Rev. Int. Med, trop. São Paulo. No prelo.

10. MENEZES, H. - II - The avirulence of the cultivated $\mathrm{Y}$ strain of Trypanosoma cruzi. Em preparo.

11. MENEZES, H. -- Active immunization of mice with the avirulent $Y$ strain of Trypanosoma cruzi against heterologous virulent strains of the same parasite. Rev. Inst. Med. trop. São Paulo. No prelo.

12. MENEZES, H. - Lesões histológicas do coração em cães "vacinados" com uma cepa avirulenta do Trypanosoma cruzi. Rev. Bras. Med. No prelo.

13. MENEZES, $\mathrm{H}$. - Active immunization of dogs with a non virulent strain of Trypanosoma cruzi. Rev. Inst. Med. trop. Săo Paulo. No prelo.

14. SENECA, H. - Current status of immunization of laboratory animals with $T$. cruzi lipopolysacharide. 8.th $^{\text {th }}$ Int. Cong. Trop. Med. \& Malaria. Teheran. 1968. Abstracts \& Reviews. Pag. 367. 